\title{
The anti-osteoporotic effect of Moringa oliefera on osteoblastic cells: SaOS 2
}

\author{
Chirag Patel ${ }^{1}$, Ayaz Rangrez ${ }^{2}$, Pragna Parikh ${ }^{3}$ \\ ${ }^{1,2 \& 3}$ (Department of Zoology, Faculty of Science, The Maharaja Sayajirao University of Baroda, Vadodaara, \\ India)
}

\begin{abstract}
M.oliefera oliefera (MO) is a middle-sized tree, cultivated throughout India. It is a multipurpose tree, used as a vegetable, spice, a source of cooking and cosmetic oil and as a medicinal plant. It is reported to contain alkaloids, flavonoids, anthocyanins. It possesses anti-inflammatory, antioxidant, antimicrobial, antihyperlipidaemic, antifertility and anticancer activities. An in-vivo study in our laboratory has proved the osteoprotective potential of the plant. In the present study an attempt is made to explore the osteoblastogenic potential of the different parts of the plant on the osteoblast cell line SaOS2. Methanolic extracts of MO components showed a positive effect, and of all the three components, flower and fruit were found to have significant osteoblast stimulating property. Flower extract was found to be increasing the number of osteoblastic cells; while the fruit extract was having more elaborative effect as it increased ALP activity, induced bone formation, increased hydroxyproline content and bone mineral formation. In conclusion, Methanolic Extact of MO on SaOS2 cell line affirmed the beneficial effects and thus indicates its potential in preventing osteoporosis.
\end{abstract}

Keywords- MO, MO Flower, MO Fruit, MO Leaves, Moringa oliefera, Osteoblasts, SaOS2

\section{Introduction}

Osteoporosis is a multifactorial disease influenced by genetic and various environmental factors. It leads to reduction in a bone mass and microarchitectural deterioration of the tissue, leading to skeletal fragility and possibilities of fracture, worsening the life of the patient. Osteoporosis arises due to loss of bone integrity which mainly depends on complexly coupled activity of osteoblastic bone formation and osteoclastic bone resorption [1]. Hence, osteoporotic drugs are designed targeting these two basic processes; especially post menopausal osteoporosis. Post menopausal bone loss is the most common cause of osteoporosis in females [2]. Estrogen Replacement Therapy can relieve the patient from few problems associated with post menopausal syndrome. However, this therapy is not having any compliance as it poses a greater threat of breast and endometrial cancer [3]. In addition, other alternative therapies developed in last few decades as pharmaceutical agents are not affordable for common man. Thus an alternative approach is required to develop new therapeutic drugs, which are safer, cheaper and easily available on global scale. Of all these alternative therapies, recently herbal medicine is gaining its importance because of its wider availability and cost effectiveness.

Osteoblasts are characterized by their ability to synthesize and secrete collagen like extra-cellular protein molecules and inducing the mineralization of this matrix via secretion of ALP like enzymes $[4,5]$. Hence, ALP activity is considered to be one of the most significant markers of osteoblastic activity. For studying osteoblastic activity in vitro, various cell lines have been developed, out of which $\mathrm{SaOS} 2$ cell line has been considered to be the most promising cell line. Though transformed, it expresses all phenotypes of osteoblastic cells making them a good model for studying osteoporosis in vitro [6,7].

After conducting several experiments on MO and understanding its osteoprotective effect, it was learned that this plant is having miraculous effect on bone integrity and it potently prevents osteoporosis. Various workers have indicated that this plant is having various phytochemicals, especially phytoestrogens which can have positive effect on bone [8]. Recent work by Zhang and co-workers [9] has shown that flavonoids can stimulate osteoblastic proliferation and differentiation. In another study, Vali and his collogues [10] also proved that Epigallocatechin-3-gallate like flavonoids induce bone mineralization and bone nodule formation. As MO flower and fruit are rich in various flavonoids and phytoestrogens, one can speculate about osteoblastogenic potential of this plant. Hence, it was designed to explore the components of MO for their effect on osteoblastic cells.

\section{Methods And Materials}

\subsection{Chemicals}

Sodium $\beta$-glyecerophosphate was purchased from Sigma Chemicals. Methanol and Triton X -100 were of Domestic AR grade products. DMEM, $100 \mathrm{X}$ antimicrobial antifungal solutions, Accutase and FBS 
were purchased from High Media Chemicals. 0.23 $\mu$ filter were purchased from Sartorius. Calcium and Alkaline Phosphatase (ALP) Kits were purchased from Reckon Diagnostic Kits Pvt. Ltd.

\subsection{Preparation of Extract}

Fruits, leaves and flowers of MO was obtained and standardized as per our previous studies [11]. Dried powder was prepared by drying MO in oven at $50^{\circ} \mathrm{C} .100 \mathrm{gm}$ dried powder of each component was extracted with $500 \mathrm{ml}$ methanol in Soxhlet's apparatus for 48 hours . Methanolic extract was dried on water bath at $55^{\circ} \mathrm{C}$. The percentage yield of the plant was found to be $9.8 \%, 6.3 \%$ and $7.7 \%$ for fruits, leaves and flowers respectively. The plant extract was freeze dried and stored at $-70^{\circ} \mathrm{C}$. Working solution was prepared by dissolving the extract in DMEM and filtered using $0.23 \mu$ filter.

\subsection{SaOS 2 cell line culture}

$\mathrm{SaOS} 2$ cell line was obtained from NCCS, Pune and cultured as described previously [12]. Briefly, the cell line was procured from the NCCS (National Center for Cell Sciences, Pune Maharastra, India). The cells were cultured in a humidified atmosphere $\left(5 \% \mathrm{CO}_{2}, 95 \%\right.$ air $)$ at $37^{\circ} \mathrm{C}$ in Dulbecco's Modified Eagle's Medium (DMEM) containing 1\% anti microbial and anti fungal solution, supplemented with 15\% FBS (High Media, Bombay). Upon reaching confluence, the cells were detached using Accutase (High Media, Bombay) and loaded in 96 well plate (Merck Scientific, Bombay) for culturing for 96 hours in 6 increasing concentration $(10 \mu \mathrm{g} / \mathrm{mL}$, $20 \mu \mathrm{g} / \mathrm{mL}, 50 \mu \mathrm{g} / \mathrm{mL}, 100 \mu \mathrm{g} / \mathrm{mL}, 200 \mu \mathrm{g} / \mathrm{mL}, 400 \mu \mathrm{g} / \mathrm{mL}$ ) of all three different extracts of leaf, flower and fruit of MO plant. After 96 hours, MTT and ALP assays were carried out to understand the effect of the plant extract on osteoblastic cells.

\subsection{MTT test}

SaOS-2 were incubated in a DMEM containing $15 \%$ FBS under partial pressure of $5 \% \mathrm{CO}_{2}$ at $37^{\circ} \mathrm{C}$. MTT assay was carried out by placing each cell into each well of 96-well plate; adding $0.05 \%$ DMSO containing samples into each well and incubating them for $72 \mathrm{~h}$; adding $0.5 \mathrm{mg} / \mathrm{mL}$ MTT into each well and further incubating them for $4 \mathrm{~h}$; dissolving produced formazan crystals in DMSO; and measuring their absorbencies at $550 \mathrm{~nm}$ using ELISA reader as described previously [13].

\subsection{Determination of Hydroxyproline and Calcium Content}

For estimation of hydroxyproline and Calcium in the culture, after 14 days of culture, the culture was lysed in $6 \mathrm{~N} \mathrm{HCl}$ for 24 hours as described previously [14,15]. After 24 hours, the solution was filtered, concentrated on sand bath to yield a white crystalline powder. This powder was then dissolved in Tris buffer $\mathrm{pH}$ 8.8 for estimation of Calcium and hydroxyproline.

\subsection{Estimation of Hydroxyproline}

Hydroxyproline estimation was carried out by the method of Neuman and Logan [16]. Briefly, the hydrolyzed samples were evaporated to dryness in a boiling water bath to remove acid, and the residue was dissolved in distilled water and made up to a known volume. It was decolorized with activated charcoal and filtered through Whatman filter paper (Tewksbury, MA, USA). For the determination of hydroxyproline, $1 \mathrm{~mL}$ of the clear filtrate was mixed with $1 \mathrm{~mL}$ of freshly prepared chloramine-T solution and allowed to stand for 20 $\mathrm{min}$. The samples were further mixed with $1 \mathrm{~mL}$ of $3.15 \mathrm{~mol} / \mathrm{L}$ perchloric acid and waited for $5 \mathrm{~min}$. Finally, 1 $\mathrm{mL}$ of freshly prepared pdimethylaminobenzaldehyde was added, mixed well, and placed in a water bath at $60^{\circ} \mathrm{C}$ for $20 \mathrm{~min}$. The absorbance of the solution was determined by using a spectrophotometer at $560 \mathrm{~nm}$.

\subsection{Statistical analysis}

All the statistical analyses were carried out using Graph pad Prism 5, and the test for significance was compared using one-way analysis of variance (ANOVA), followed by Bonferroni post hoc test [17].

\subsection{Growth of osteosarcoma}

\section{Results}

$\mathrm{SaOS} 2$ has been an established cell line for the purpose of bone research [18,19]. During the experimental period, there was no evidence of toxicity to the cells or no signs of bacterial or fungal contamination on the well chamber. The cells were found to be growing well in the culture medium after passaging.

\subsection{MTT assay}

The general principle for the detection of cell growth or cell kills via the MTT cytotoxicity assay is the conversion of the tetrazolium salt (MTT) to the coloured product formazan. The formation of formazan takes 
place via intact mitochondria. An advantage of using cultured cell lines is to investigate fundamental aspects of drug-metabolism-linked toxicity. For MTT assay the effectiveness of the agent in causing death, or changing metabolism of cells, can be deduced through the production of a dose-response curve. The effect of all the three components is represented in TABLE 1. Of all the 3 components, MO leaf extract did not show any osteoblastogenic potential. In addition it was found to be toxic at higher doses, where it reduced ALP activity to $62 \%$ at $400 \mu \mathrm{g} / \mathrm{mL}$ dosages (Fig.1). Flower extract showed most promising results where it increased the cell viability in a dose dependent manner. However, at very high dose of $200 \mu \mathrm{g} / \mathrm{mL}$ and $400 \mu \mathrm{g} / \mathrm{mL}$ it did not show further increase; suggesting that its therapeutic dose is between $50 \mu \mathrm{g} / \mathrm{mL}$ to $100 \mu \mathrm{g} / \mathrm{mL}$ (29\% increase) (Fig.2). Fruit extract also showed osteoblast stimulating potential, but its efficacy was lower compared to flower extract, where maximum stimulation was observed with $100 \mu \mathrm{g} / \mathrm{mL}$ dosage (18\% increase, $\mathrm{p}$ value <0.01) (Fig.3). At further higher doses, it lost its osteoblast stimulating potential.

\subsection{ALP activity}

ALP activity is one of the most established marker of studying osteoblastic activity. Our results indicated that only flower and fruit extract had osteoblast stimulating potential; while Leaf extract was found to be inhibiting osteoblastic activity (TABLE- 2). Though at lower doses leaf extract did show insignificant increase in osteoblast activity, at higher doses it was found to be inhibiting ALP activity (Fig.4). Flower extracts showed more promising results where it increased ALP activity in a dose dependent manner; showing almost 4 fold increases in ALP activity at $400 \mu \mathrm{g} / \mathrm{mL}$ dosage. It started exerting its positive effect on osteoblastic cells at even a very low dose of $10 \mu \mathrm{g} / \mathrm{mL}$ where it showed 2 fold increase in ALP activity (p value<0.05) (Fig.5). MO fruit showed similar dose dependent effect; where it showed 6 fold increase in ALP activity at $200 \mu \mathrm{g} / \mathrm{mL}$ dosage. However, further dose dependency was not observed with $400 \mu \mathrm{g} / \mathrm{mL}$ dosage (Fig.6). Results of ALP activity showed that both flower and fruit of MO had potent effect on increasing the ALP activity by osteoblastic cells.

\subsection{Calcium content in the lysate}

It was observed from the previous experiments that $\mathrm{MO}$ components exert their effectiveness only at higher doses of $100 \mu \mathrm{g} / \mathrm{mL}, 200 \mu \mathrm{g} / \mathrm{mL}$ and $400 \mu \mathrm{g} / \mathrm{mL}$, Hence, calcium estimation in the given lysate was carried out only for these 3 doses. TABLE 3 shows variation in calcium content due to MO extracts treatment. As expected, leaf extract did not show any increase in the calcium content. At $400 \mu \mathrm{g} / \mathrm{mL}$ it decreased the calcium content; but the data was non-significant (Fig.7). Flower extract showed increase in the calcium content; maximum calcium content was observed with $400 \mu \mathrm{g} / \mathrm{mL}$ (33\% increase) (Fig.8). However, fruit extract was found to be most potent in increasing the calcium content in the lysate. At $200 \mu \mathrm{g} / \mathrm{mL}$ dosage it showed almost 50\% increase in the calcium content, suggesting its mineralizing potential (Fig.9). However, the data was not found to be dose dependent, as at $400 \mu \mathrm{g} / \mathrm{mL}$ dosage it showed nonsignificant increase in calcium content.

\subsection{Hydroxyproline content in the lysate}

Hydroxyproline is one the most important amino acids that play a key role in collagen assembly in the bone matrix synthesis. Effect of various components of MO is shown in TABLE 4. Leaf extract had negative effects on hydroxyproline content in the lysate. At $400 \mu \mathrm{g} / \mathrm{mL}$ dosage it showed negative effect on hydroxyproline content; where it reduced hydroxyproline levels to 50\% compared to vehicle (Fig.10). Flower extract showed non significant increase in the hydrxyproline levels (Fig.11). Fruit extract showed promising results; where it boosted the hydroxyproline levels and maximum effect was observed at $100 \mu \mathrm{g} / \mathrm{mL}$ dosage where it almost doubled the hydroxyproline content in the lysate (Fig.12). At higher doses of $200 \mu \mathrm{g} / \mathrm{mL}$ and $400 \mu \mathrm{g} / \mathrm{mL}$ also it showed increase in the hydroxyproline content.

\section{Discussion}

Over the past two decades various studies have been published, presenting the role of Moringa oliefera as a potent pharmaceutical agent, one of which was describing its osteoprotective effect in ovariectomized wistar rats (Burali et al., 2009). However, He did not provide clue about the mechanism behind its osteoprotective effect. The present study is the first report to provide scientific data about the probable cellular mechanism behind the osteoprotective effect of different components of MO. In the present study we have shown that MO is having osteoblast stimulating property, as it boosted all the markers of osteoblast activity. Of all the three components of MO, fruit and flower extract were having significant osteoblast proliferating and stimulating property.

In a recent study by Vali and coworkers [10] it was shown that certain flavonoids can have positive effect on bone nodule formation in vitro. As MO is rich in certain flavonoids [20], they might be the one playing a key role in stimulating osteoblastic cells. Our results are in accordance with Wang and his team [29] who 
showed that flavonoids are having osteoblast stimulating potential. In the previous studies [8], where MO fruit extract was shown to be having positive effect on bone loss; it was also shown to be having positive effect on calcium balance. Furthermore, Rangrez and his co workers [11] showed that MO is preventing bone loss in ovariectomy induced bone loss. However, whether it promotes bone formation or prevents bone loss, was unclear till the findings of this study; which showed that MO flower and fruit extract not only increased the ALP activity; it also increased the calcium content in the culture; suggesting that MO increases the osteoblastic activity; leading to more bone formation, a probable cellular mechanism behind the osteoprotective effect of this plant.

Osteosarcoma cell line SaOS 2 serves as an ideal replacement for primary culture of Human Osteoblastic cells obtained by either human explants technique [21] or human bone marrow [22]. Primary culture of human osteoblastic cells is a tedious process and they can be used only once after first passaging [23]. Moreover they grow very slowly and require long times for a confluent growth [24]. Hence, their maintenance is costly and they change their phenotype after few passaging. Because of their heterogenous nature, response of human osteoblastic cells is also age dependent and hence in last decade, transformed cell lines are gaining importance [25]. Of all the transformed cell lines, $\mathrm{SaOS} 2$ is considered to be the best; because of their stable phenotype, fast growth and expression of all osteoblastic features; including bone nodule formation [26].

Bone formation is a 3 staged process, namely; proliferation of osteoblasts; secretion of extract cellular matrix by osteoblasts and mineralization [4]. ALP activity is an established marker of osteoblast activity. We observed that MO flower and fruit extract treatment increases the ALP activity. This rise in the ALP activity with herbal treatment indicates that MO extract differentiates osteoblastic cells towards the bone forming phenotype. Of all the three components, leaf extract did not show any rise in ALP activity. Compared to leaf extract, both flower and fruit showed positive effect on this osteoblastic function marker. However, flower was found to be less potent in stimulating ALP activity compared to fruit. But when this data was considered with MTT assay, it showed contrasting results where fruit extract was found to be promoting osteoblast cell division. Hence, by combining these two results, one develops an understanding that MO fruit extract increases the number of osteoblastic cells, favoring their proliferation, while fruit extract not only increases the number but also stimulates them to undergo differentiation into mature bone forming cells. Hence, both the extracts, though favoring bone formation, their mechanism of action was slightly different, as flower helps to increase the osteoblast number, while fruit increases its activity and mineralization as well.

It is an established fact that osteoblast number or ALP alone does not account for the bone formation. Hence, we used both calcium and hydroxyproline estimation to confirm the osteoblastic activity. Calcium is the chief constituent of the bone mineral hydroxyapetite, while hydroxyproline is an important aminoacid required for the formation of collagen; constituent of the bone matrix [27]. Our results, however, showed positive activity on both the parameters, suggesting that these plant components are having positive effect on bone osteoblastic cell growth, their activity, synthesis of bone matrix and its mineralization.

Though various studies have established the role of MO fruit extract on different cell types; very few studies have been conducted till now on flower extract. Moringa flower is known to be rich in a well recognized flavonoid, quercetin, which is a proven antioxidant as well as a potent osteoblast stimulating agent [28]. However, no reports are available describing the effect of flower extract on osteoblastic cells. In this study, we discovered that MO flower is not only increasing the activity of osteoblastic cells; it also promotes the osteoblastic cell division, making it a more potent osteoprotective agent. At higher doses where MO fruit extract showed lower activity, flower extract was found to be having dose dependent activity on all parameters. To our knowledge, this study is the first to explore various components of MO for their osteoprotective effect in vitro on osteoblastic cells $\mathrm{SaOS} 2$.

In summary, our results demonstrated that MO components are having positive effect on osteoblastic cells. Of all the three components; leaf, flower and fruit, leaf extract was not found to be having any effect on osteoblastic cells. Compared to flower and fruit extracts were found to be having positive effect on bone cells. Flower extract was found to be increasing the number of osteoblastic cells; while the fruit extract was having more elaborative effect as it increased ALP activity, induced bone formation, increased Collagen content and bone mineral formation. It has been well documented that agents stimulating osteoblast proliferation, differentiation, mineralization and survival are potent osteoprotective agents. Our study proved that MO flower and fruit extract have all these properties and hence they are one of the most potent future candidates for osteoporosis treatment. 
Table 1 - Showing effect of different components of MO on SaOS 2 cell viability $\%$

\begin{tabular}{|c|c|c|c|}
\hline $\begin{array}{c}\text { Dose } \\
(\mu \mathrm{g} / \mathrm{ml})\end{array}$ & LEAVES & FLOWER & FRUIT \\
\hline Vehicle & $98.24 \pm 5.36$ & $97.44 \pm 4.23$ & $96.23 \pm 1.69$ \\
\hline 10 & $102.36 \pm 5.31$ & $104.26 \pm 3.69$ & $96.45 \pm 4.12$ \\
\hline 20 & $106.36 \pm 9.36$ & $108.56 \pm 4.23$ & $106.23 \pm 9.18$ \\
\hline 50 & $101.36 \pm 8.98$ & $112.46 \pm 9.36$ & $110.12 \pm 3.25$ \\
\hline 100 & $112.49 \pm 7.94$ & $129.26^{* * * * *} \pm 8.45$ & $118.42 \pm 6.36$ \\
\hline 200 & $93.26 \pm 7.79$ & $124.85^{* * *} \pm 8.10$ & $100.23 \pm 5.36$ \\
\hline 400 & $62.37^{* * * * *} \pm 3.38$ & $129.45^{* * * * *} \pm 4.24$ & $103.81 \pm 5.89$ \\
\hline
\end{tabular}

Values were expressed Mean \pm S.E.M. $*-\mathrm{p}<0.05 ; * *-\mathrm{p}<0.01 ; * * *-\mathrm{p}<0.001$

Table 2 - Showing effect of different components of MO on SaOS 2 ALP activity \%

\begin{tabular}{|c|c|c|c|}
\hline $\begin{array}{c}\text { Dose } \\
(\mu \mathrm{g} / \mathrm{ml})\end{array}$ & LEAVES & FLOWER & FRUIT \\
\hline Vehicle & $9.93 \pm 1.04$ & $9.71 \pm 1.53$ & $9.81 \pm 1.93$ \\
\hline 10 & $6.47 \pm 2.41$ & $17.54^{*} \pm 0.22$ & $12.33 \pm 3.55$ \\
\hline 20 & $13.00 \pm 0.66$ & $14.36 \pm 3.47$ & $14.23 \pm 3.47$ \\
\hline 50 & $12.57 \pm 2.66$ & $17.36 \pm 5.64$ & $25.36^{* *} \pm 4.95$ \\
\hline 100 & $6.24 \pm 3.96$ & $29.13^{* * * *} \pm 3.69$ & $55.03^{* * * * *} \pm 4.02$ \\
\hline 200 & $4.33^{* * *} \pm 2.73$ & $35.69^{* * * * *} \pm 3.71$ & $39.38^{* * * * *} \pm 7.79$ \\
\hline 400 & $4.35^{* * \pm} \pm 4.18$ & $26.45^{* * * * 1} \pm 3.38$ & $33.37^{* * * * *} \pm 3.38$ \\
\hline
\end{tabular}

Values were expressed Mean \pm S.E.M. $*-\mathrm{p}<0.05 ; * *-\mathrm{p}<0.01 ; * * *-\mathrm{p}<0.001$

Table 3-Showing effect of different components of MO on Calcium content in the lysate\%

\begin{tabular}{|c|c|c|c|}
\hline $\begin{array}{c}\text { Dose } \\
(\mu \mathrm{g} / \mathrm{ml})\end{array}$ & LEAVES & FLOWER & FRUIT \\
\hline Vehicle & $29.26 \pm 2.35$ & $29.26 \pm 2.35$ & $29.26 \pm 2.35$ \\
\hline 100 & $24.26 \pm 4.26$ & $34.13 \pm 1.24$ & $39.25^{*} \pm 4.11$ \\
\hline 200 & $26.56 \pm 4.53$ & $31.26 \pm 3.67$ & $45.12^{* *} \pm 4.23$ \\
\hline 400 & $22.16 \pm 3.27$ & $39.23^{* * *} \pm 2.34$ & $35.26 \pm 3.13$ \\
\hline
\end{tabular}

Values were expressed Mean \pm S.E.M. $*-\mathrm{p}<0.05 ; * *-\mathrm{p}<0.01 ; * * *-\mathrm{p}<0.001$

Table 4-Showing effect of different components of MO on Hydroxyproline content in the lysate\%

\begin{tabular}{|c|c|c|c|}
\hline $\begin{array}{c}\text { Dose } \\
(\mu \mathrm{g} / \mathrm{ml})\end{array}$ & LEAVES & FLOWER & FRUIT \\
\hline Vehicle & $13.25 \pm 1.46$ & $13.25 \pm 1.46$ & $13.25 \pm 1.46$ \\
\hline 100 & $7.24 \pm 4.24$ & $18.24 \pm 1.22$ & $26.15^{* * *} \pm 1.33$ \\
\hline 200 & $11.24 \pm 5.36$ & $15.36 \pm 5.36$ & $22.45^{*} \pm 1.34$ \\
\hline 400 & $7.25 \pm 4.24$ & $11.85 \pm 5.64$ & $24.67^{*} \pm 6.99$ \\
\hline
\end{tabular}

Values were expressed Mean \pm S.E.M. * $-\mathrm{p}<0.05 ; * *-\mathrm{p}<0.01 ; * * *-\mathrm{p}<0.001$ 

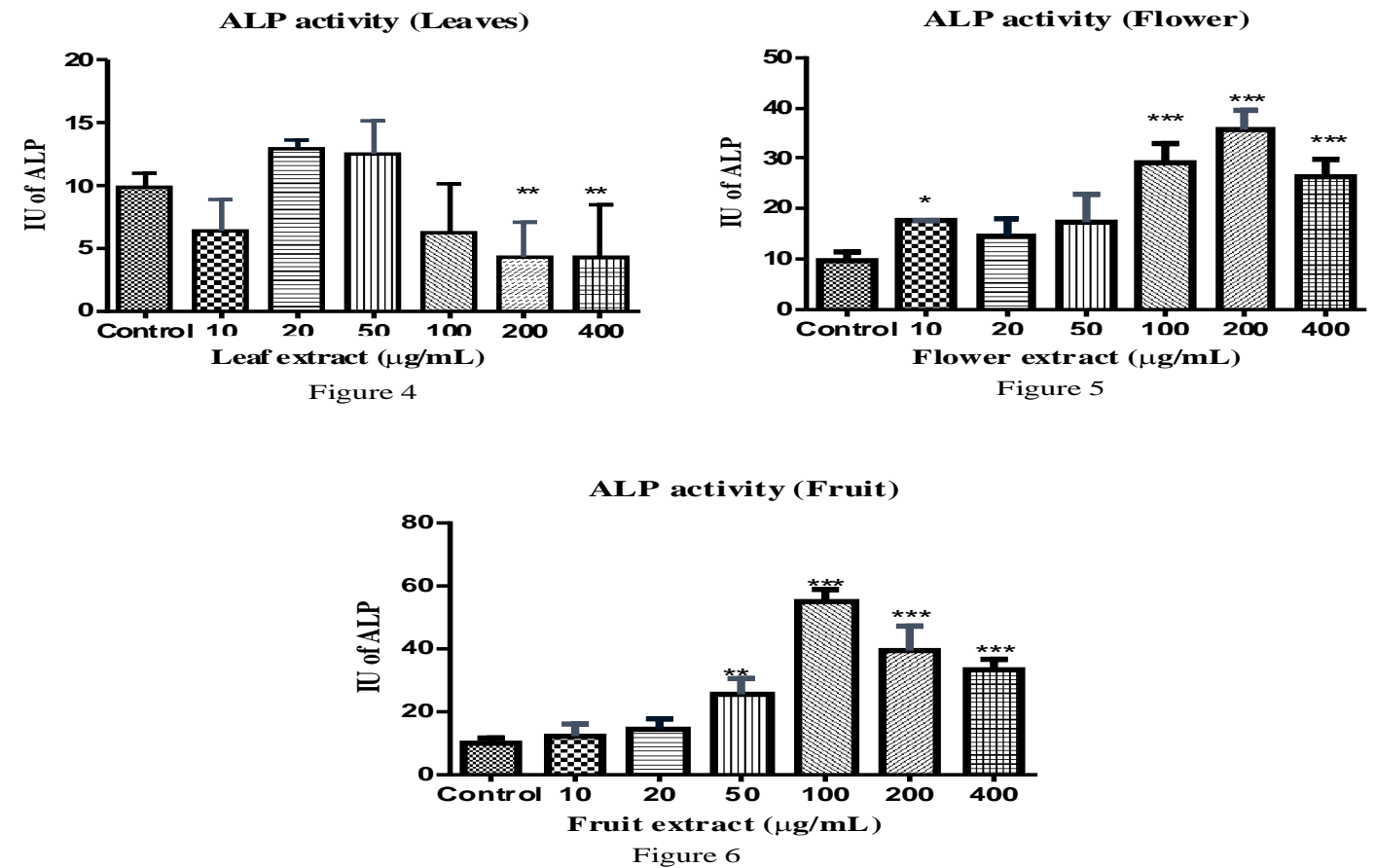

Figure 4: A LP activity (Leaves):

Figure 5: A LP activity (Flower)

$\mathrm{S}$

Figure 6: A LP activity (Fruit)
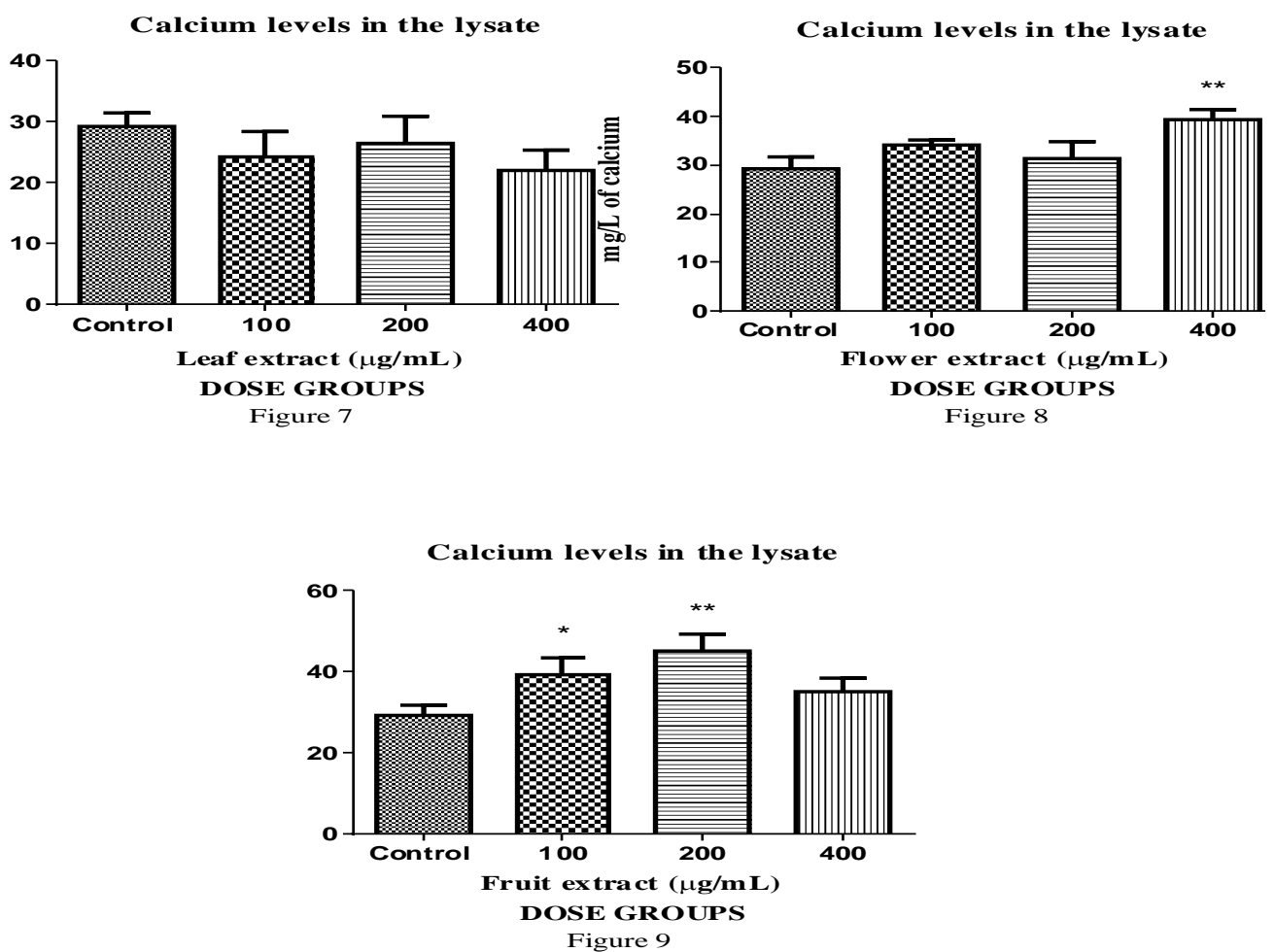

Figure 7: Calcium levels in the lysate (Leaf);

Figure 8: Calcium levels in the lysate (Flower);

Figure 9: Calcium levels in the lysate (Fruit) 

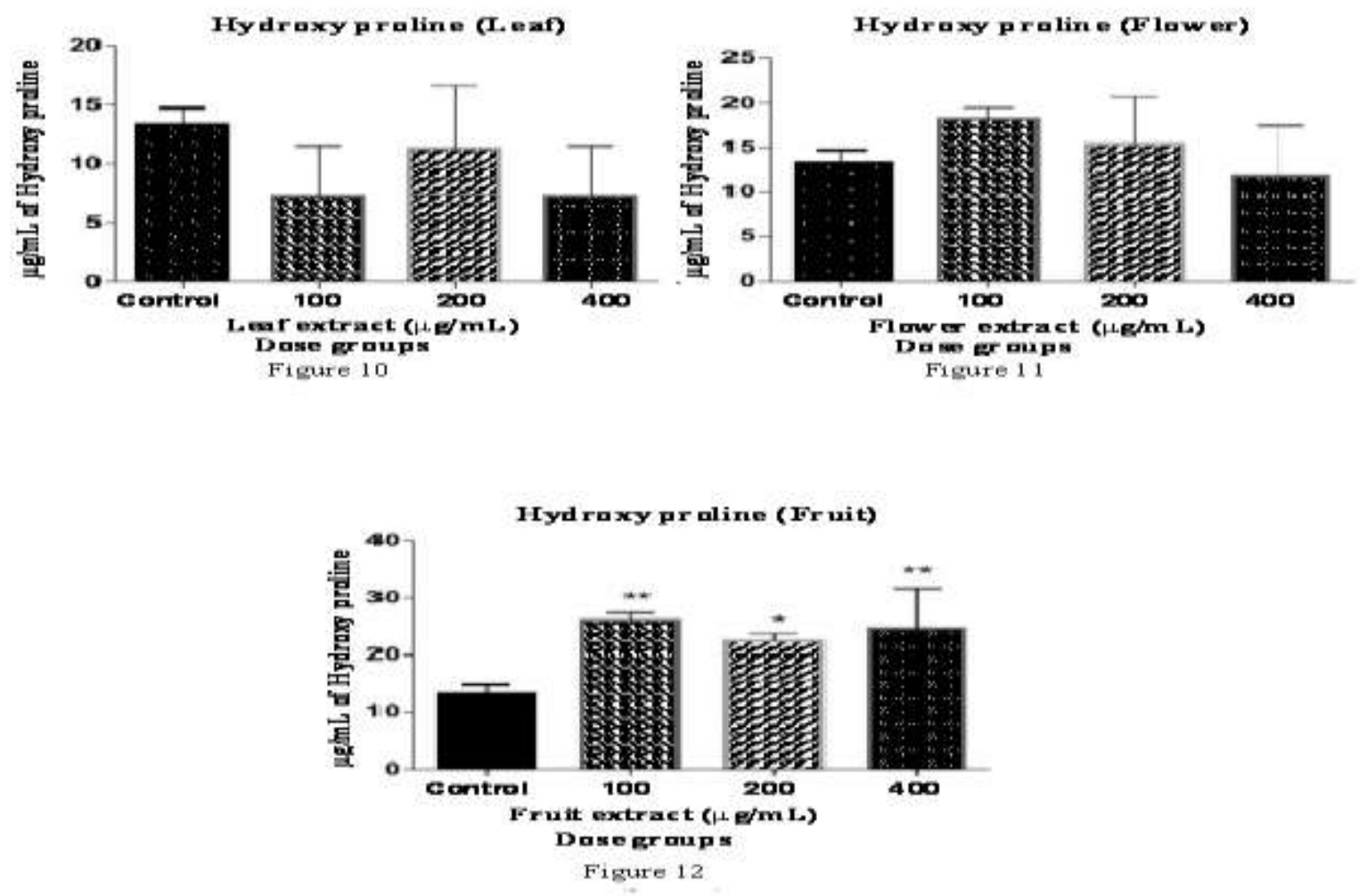

Figure 10: Hydroxyproline levels in the lysate (feaves):

Figure 11: Hydroxyproline levels in the lysate (Flower):

Figure 12: Hydroxyproline levels in the lysate (Fruit)

\section{References}

[1] Riggs and Melton, The Prevention and Treatment of Osteoporosis, New England Journal of Medicine 327, 1992, 620-627.

[2] North American Menopause Society, Management of osteoporosis in postmenopausal women: 2010 position statement of the North American Menopause Society, Menopause, 17(1), 2010, 25-54.

[3] Persson I, Weiderpass E, Bergkvist L, Bergstrom R, Schairer C., Risks of breast and endometrial cancer after estrogen and estrogenprogestin replacement. Cancer Causes Control 10(4), 1999, 253-260.

[4] Aubin, J.E., Advances in osteoblast lineage, Biochem cell biol., 76, 1998, 899-910.

[5] Lian JB, Stein GS, Stein JL, Wijnen AJ van, Regulated expression of the bone specific osteocalcin gene by vitamins and hormones, Vitam Horm., 55, 1999, 443-509.

[6] Rodan, S.B., Imai, Y., Thiede, M.A., Wesolowski, G., Thomson, D., Barshvit, Z. et al., Characterization of a human osteosarcoma cell line $\mathrm{SaOS} 2$ with osteoblastic properties, Cancer Res., 47, 1987, 49-66.

[7] Rao, L.G. and Murray, T.M., Studies of human osteoblasts in vitro: Estrogen actions and interactions with other hormones at different stages of differentiation, Drug Dev Res., 49(3), 2000, 174-186.

[8] Burali, S.C., Kangralkar, V., Sravani, O. and Patil, S.L., The beneficial effect of ethanolic extract of moringa oleifera on osteoporosis, International journal of pharmaceutical applications, 1(1), 2010, 50-58.

[9] Zhang D.W., Cheng Y., Wang N.L., Zhang J.C., Yang M.S., Yao X.S., Effects of total flavonoids and flavonol glycosides from Epimedium koreanum Nakai on the proliferation and differentiation of primary osteoblasts, Phytomedicine 15(1-2), 2008, 55-61.

[10] Vali B., Rao L.G., El-Sohemy A., Epigallocatechin-3-gallate increases the formation of mineralized bone nodules by human osteoblast-like cells, Journal of Nutritional Biochemistry 18(5), 2007, 341 - 347.

[11] Rangrez A.Y., Balakrishnan S. and Parikh P.H., Osteoprotective effect three anti inflammatory plants in ovariectomized wistar rats, Pharmacologyonline 1,2011, 675-684.

[12] Thangakumaran, S., Sudarsan, S., Arun, K.V., Talwar, A., James, J.R., Osteoblast response (initial adhesion and alkaline phos phatase activity) following exposure to a barrier membrane/ enamel matrix derivative combination, Indian Journal of Dental Research, 20(1), 2009, 7-12.

[13] Ha H, Ho J, Shin S, Kim H, Koo S, Kim IH, Kim C., Effects of Eucommiae Cortex on osteoblast-like cell proliferation and osteoclast inhibition, Archives Pharmacal Research, 26(11), 2003, 929-36.

[14] Woessner J. F., Determination of hydroxyproline in connective tissues, The methodology of connective tissues research (Oxford, Johnson-Bruvvers Ltd., England: Hall D.A, 1976, 235-45).

[15] Roveri, E.A., Chap, G., Grappiolo, I. and Puche, R.C., Effects of depot medroxyprogesterone acetate on the calcium metabolism of adult ovariectomized rats. Medicine, 60, 2000, 482-486.

[16] Neuman R.E., Logan M.A., The determination of collagen and elastin in tissues, J Biol Chem 186, (1950), 549-556.

[17] Parikh, P., Suresh, B. and Rangrez, A., Osteoprotective effect of Litsea glutinosa in ovariectomized wistar rats, Electronic Journal of Pharmacology \& Therapy, 2, 2009, 81-86. 
[18] Rodan, S.B., Imai, Y., Thiede, M.A., Wesolowski, G., Thomson, D., Barshvit, Z. et al., Characterization of a human osteosarcoma cell line SaOS 2 with osteoblastic properties. Cancer Res., 47, 1987, 4961-4966.

[19] Richard, J., David, W. and Timothy, R., Isolation and culture of osteoclasts and osteoclast resorption assays, Methods in bone biology (Chapman \& Hall, London, UK: Timothy R., Arnett and B. Henderson 1997, 64-105)

[20] Das S., Kanodia L., Effect of ethanolic extract of leaves of Moringa olifera lam. On acetic acid induced colitis in albino rats, Asian Journal of Pharmaceutical and Clinical Research, 5(3), 2012, 110-14.

[21] Kung Sutherland M.S., Rao L.G., Muzzafar S.A., Wylie J.N., Wong M.M., McBroom R., et al., Age-dependent expression of osteoblastic phenotypic markers in normal human osteoblasts cultured long term in the presence of dexamethasone. Osteoporosis International, 5(5), 1995, 335-43.

[22] Kassem M, Risteli L, Mosekilde L, Melsen F, Eriksen EF., Formation of osteoblast-like cells from human mononuclear bone marrow cultures, APMIS, 99(3), 1991, 269-74.

[23] Robey P.M., Termine J.D., Human bone cells in vitro, Calcified Tissue International, 37(5), 1985, 453-60.

[24] Wong M.M., Rao L.G., Ly H., Hamilton L., Sturtridge W., McBroom R., et al., Long term effects of physiological concentrations of dexamethasone on human bone-derived cells, Journal of Bone and Mineral Research, 5(8), 1990, 803-13.

[25] Matsuyama T., Lau K., Wergedal J.E., Monolayer cultures of normal human bone cells contain multiple subpopulations of alkaline phosphatase positive cells, Calcified Tissue International, 47(5), 1990, 276-83

[26] Manduca P., Sanguineti C., Pistone M., Boccignone E., Sanguineti F., Santolini F., et al., Differential expression of alkaline phosphatase in clones of human osteoblast-like cells, Journal of Bone and Mineral Research, 8(3), 1993, 291-300.

[27] George B.O., Urinary and anthropometrical indices of bone density in healthy Nigerian adults, Journal of Applied Sciences \& Environmental Management, 7(1), 2003, 19-23.

[28] Selvakumar1 D., Natarajan P., Hepato-protective activity of Moringa oleifera lam leaves in Carbon tetrachloride induced hepatotoxicity in albino rats, Pharmacognosy Magazine, 4(13), 2008, 97-98.

[29] Wang D., Li F., Jiang Z., Osteoblastic proliferation stimulating activity of Psoralea corylifolia extracts and two of its flavonoids, Planta Med., 67(8), 2001, 748-9. 